\title{
Aparición y desaparición del camino amoroso en la obra de Jaime Saenz: Análisis de un capítulo de Felipe Delgado'
}

Camilo Gil Ostria

\author{
Universidad Mayor de San Andrés
}

\begin{abstract}
A This essay proposes a close reading of chapter VIII of the second part of Felipe Delgado, a novel by Jaime Saenz. In this chapter, which narrates Felipe's birthday, the projection process by which the protagonist dominates his world is staged; at the same time, Ramona (and the intruder into whom she will transexualize) will neutralize that dominant gaze. Comparing the chapter with Magritte's series The Lovers and Barthes's A Lover's Discourse: Fragments, the importance of the amorous path will be brought to the fore in this novel.
\end{abstract}

Keywords

Amorous path, Felipe Delgado, Jaime Saenz, transexualization

\footnotetext{
${ }^{1}$ Este ensayo es una versión corregida y aumentada de la ponencia "Felipe Delgado: entre el intruso y el marica" presentada en el marco de las Jornadas Andinas de Literatura Latinoamericana (JALLA), México-2020. Disponible en el sitio web de JALLA 2020: https://www.facebook.com/ceiich.unam.mx/videos/1675166745977503
} 


\title{
Resumen
}

Este ensayo propone una lectura detallada del capítulo VIII de la segunda parte de Felipe Delgado, novela de Jaime Saenz. En este capítulo, que narra el cumpleaños de Felipe, se pone en escena el proceso de proyección por el que el protagonista domina su mundo; al mismo tiempo, Ramona (y el intruso en quien se transexualizará) neutralizarán esa mirada dominante. Comparando el capítulo con la serie Los amantes, de Magritte, y con Fragmentos de un discurso amoroso, de Barthes, se pondrá en escena la importancia del camino amoroso en esta novela.

\section{Palabras clave}

Camino amoroso, Felipe Delgado, Jaime Saenz, transexualización

\author{
Hazme saber, perdida y desaparecida visión, qué \\ era lo que guardaba tu mirar \\ -si era el ansiado y secreto don, \\ que mi vida esperó toda la vida a que la muerte \\ lo recibiese.
}

Aniversario de una visión, Jaime Saenz

Felipe Delgado (1979), primera novela del famoso escritor paceño Jaime Saenz (1921-1986), narra la búsqueda del protagonista homónimo de "quitarse el cuerpo" en cuatro partes: la primera se abre con la muerte de su padre y la instauración - mediante el alcohol- de un espacio: la bodega. La segunda se centra en su encuentro amoroso con Ramona Escalera. La tercera cuenta un empezar a retirarse de La Paz (a visitar el mar perdido, errando por los márgenes de la ciudad), hasta la marcha final a Uyupampa y el fin de la bodega. La cuarta parte pone en escena, desde la mirada de los otros personajes, el quitarse el cuerpo de Felipe, que, aunque ya ausente, "está aquí" (Felipe Delgado 628), como un Werther ${ }^{2}$ que, al suicidarse, permanece para siempre.

\footnotetext{
2 Guiño a la famosa novela del romanticismo alemán Los sufrimientos del joven Werther (1774), escrita por Johann Wolfgang von Goethe. Novela no solo relevante por la conocida admiración que Saenz habría tenido por Goethe (nombrado varias veces en sus dos novelas); sino porque Felipe Delgado, se notará al final, se nutre de los valores del romanticismo: el suicidio o el "quitarse el cuerpo" son análogos.
} 
En este ensayo nos centraremos en la segunda parte, pues esta "encarna [los] restos que exceden" el Bildungsroman (Villena 2012, 39), es decir, el proyecto saenziano. ${ }^{3}$ En ella, como se verá en el capítulo a tratar, el otro juega a desaparecer y aparecer, lo que rompe la mirada ordenadora de este proyecto, proponiendo una indescriptible alteridad. El juego deja de sostenerse cuando el otro se transexualiza. Entenderemos este neologismo en el sentido de un cambio de sexo (de hombre a mujer, de mujer a hombre) que, en tal proceso, confirma las nociones de género y sexo como binarias. ${ }^{4}$ Así, se aleja de lo "Neutro" barthesiano, de otra posibilidad de alteridad que, en la obra de Saenz, no se sostiene..$^{5}$ Los personajes, tras la transexualización, vuelven a encajar en una visión binaria del mundo (es un Mal Neutro, como veremos más adelante) y escapan del camino amoroso.

Se tratará de explicar lo Neutro y sus diferencias con lo queer ${ }^{6}$ a lo largo del texto a analizar. De entrada, diremos que es necesario - para que tal

\footnotetext{
${ }^{3}$ Marcelo Villena, a partir de la lectura de Antezana ("Felipe Delgado de Jaime Saenz") entiende Bildungsroman en el sentido de Bajtín. Es decir, como una novela donde un protagonista pasa, mediante varios sucesos que se van acumulando y formándolo, de un estado a otro. Esto tiene ciertos requisitos estructurales: lo de un relato lineal, con un objetivo fijo, etc. Y señala que esto se relaciona a un "proyecto saenziano" mayor: el de la vida (ver la sección 2 de este ensayo para mayor detalle).
}

4 "Esto explica por qué el transexual es un verdadero obstáculo epistemológico para ellos, ya que nadie cree más en la diferencia sexual que un verdadero transexual", señala Jacques-Alain Miller en su entrevista a Éric Marty (S/P). En ella también se hace una dura crítica al movimiento de Judith Butler y la noción de género que, para los autores, también sería más fija de lo que la autora quisiera ver. Por lo tanto la señalan como un "significante Amo". Aquí diríamos, parte de un Imaginario, de lo estereotípico.

5 Partimos de la lectura de lo Neutro de Éric Marty. En su ensayo "Sobre los Fragmentos de un discurso amoroso. Reflexiones sobre la imagen" incluido en Roland Barthes, el oficio de escribir, define lo Neutro como: 1) Una paradoja: lugar donde el decir directo y el metalenguaje, por ejemplo, o el deseo y el conocimiento, no entran en contradicción (200). 2) Un proceso de "inexpresión" o suspensión (غ̇лoxń) que libera al lenguaje de "la alienación de un sentido preconstruido, de la plenitud del estereotipo, de la repetición, de la generalidad" (201). 3) la búsqueda de una alteridad que sin anular el Imaginario o la otredad como Alter Ego, se presenta "nueva, inédita, impensada por el lenguaje" (269). A ese último otro hacemos referencia en todo el ensayo al usar esa palabra.

${ }^{6}$ Diferencia entonces con la lectura de la crítica Beth Bouloukos, quien en su tesis afirma que sería lo queer lo posibilitador del camino místico y de conocimiento en toda la obra de Jaime Saenz (63-89). Ella define lo queer como lo que no encaja, como un afuera de la visión dominante, de la sociedad heteronormativa (21). Tal definición parece idealizar otro lugar y reforzar la imposibilidad de cambio de las estructuras. Estas lecturas mitificadoras o idealizadoras han sido muy comunes para la obra de Saenz. Algunos posibles motivos de esta idealización (la peculiar biografía del autor, por ejemplo) se explican en el artículo de Gilmar González "La última novela de Jaime Saenz: Los papeles de Narciso Lima-Achá". 
proceso suceda - un escenario donde, como primer paso, se haga evidente el Imaginario. Entenderemos al Imaginario, con Éric Marty, como una estructura relacional (yo-tú) que esconde la Imagen. Bajo la luz de esta idea de Imaginario, la Imagen es un otro (tú) suave, escondido, pero mostrándose. De donde se deriva una posibilidad amorosa especial, negada por el surgimiento del Alter: cambio drástico y repentino que produce la caída de la Imagen (tú suave, escondido por el Imaginario) y la revelación de ese "tú" como un otro extremo, insostenible, mas paradójicamente reducido y equiparado al "yo". ${ }^{7}$

Este escenario se da en el capítulo VIII (Felipe Delgado 241-251), que introduce a un personaje que -a través de un desencaje homosexual- rompe con la mirada de Felipe, totalizadora en la novela (algo similar sucede, aunque solo lo veremos a manera de contrapunto, en la segunda novela de Jaime Saenz, Los papeles de Narciso Lima-Achá). En este capítulo, que narra el cumpleaños del protagonista, Ramona le regala un proyector que "encerraba algún enigma" (245). Entre indirectas y directas, lo instalan y proyectan una película de Chaplin (242-243). El resto es difuso: ella afirma que ellos se han besado, Felipe no puede recordar. De hecho, piensa que solo podría haber besado al "intruso", a la "aparición que se le había aparecido" (243). Ella se va y él invita a sus dos amigos (Peña y Lillo, y Beltrán), quienes al día siguiente le cuentan todo lo acontecido: cómo llegan con un "intruso", cómo Felipe lo bautiza Ramón Delgada, cómo Ramón los expulsa y se queda solo con el cumpleañero (244-250). Finalmente, el protagonista dice que todo el cumpleaños ha sido un sueño (250-251).

Así se abren distintas preguntas que irán señalando la construcción de este espacio de otredad: 1) ¿Qué enigma guarda el proyector? 2) ¿Qué significa que Ramona hable de un beso que Felipe niega? ¿Por qué él lo niega y afirma que pudo haber sucedido con el intruso? 3) ¿Qué rol juega esta aparición? 4) ¿Qué significa que lo sucedido con el intruso sea narrado, primero, en la voz de los otros (Peña y Lillo, y Beltrán) y luego negado como un sueño? es decir, ¿por qué Felipe olvida, escapa, de lo sucedido en un espacio donde "la realidad no existiría, de no ser la irrealidad" (250)?

\footnotetext{
7 Estructura del "lenguaje y [de] la alteridad", señala Marty para definir al Imaginario (169), que habría sido perseguido por la teoría moderna como lugar de engaños e ilusiones (179-181). Por otro lado, la Imagen barthesiana es para él "una falta en lenguaje" (subrayado en el original, 252) que genera la suspensión del Imaginario; es otra forma, como se verá, de vivir la alteridad. Finalmente, esta Imagen sería destruida por el surgimiento del otro en tanto Alter ego o violencia (268).
} 
Se tratará de responder a estas preguntas mediante el ejercicio de un análisis que pondrá el foco en los códigos que componen el texto en cuestión. Dicho análisis tendrá cuatro partes: una primera que hablará sobre el reino del Imaginario, cuyo rey es Felipe Delgado; la segunda sobre cómo esa visión se posa en Ramona (a pesar de todo); la tercera sobre la caída de Ramona (en Ramón, la Imagen), y la última sobre el miedo de Felipe a ese intruso, escapando al Alter y al Imaginario.

Cada uno de los puntos será acompañado de una de las versiones, de las cuatro existentes, de Los amantes (1928), de René Magritte y de los Fragmentos de un discurso amoroso (1977), de Roland Barthes, en adelante FDA. La relación Saenz-Barthes-Magritte no solo se basa en que los tres ponen en juego la relación sujeto-otro amado; sino que también (como se tratará de mostrar) en que los tres pueden leerse ante una estructura ética de lo Neutro, del vacío, del No-Querer-Asir. Esta estructura, en los tres casos, lee el encuentro amoroso en cuatro etapas. ${ }^{8}$

Cuatro como cuatro serían las caídas que, para Marcelo Villena en su estudio introductorio a la edición de Felipe Delgado para la colección 15 Novelas Fundamentales (2012), hacen que Felipe trate de reintegrarse a la Unidad y a la Perfección. Pues él, de inicio, sería también un Cuatro: "individuo equidistante del Uno y del Siete" (43). Con esas cuatro caídas, sin embargo, diría adiós al camino amoroso. Este camino será ensayado en la segunda parte de Los Papeles de Narciso Lima-Achá, donde se narra la relación amorosa entre Narciso y Elbruz Ulme, un joven alemán de 18 años que introduce a Narciso en un viaje iniciático, un viaje de vida, un viaje en barco a Europa; hasta que Narciso lo abandona, tras verlo convertido en mujer. La relación con Ramona, para Villena, algo de eso genera, distrayendo a Felipe de la "ruta que le ha sido trazada" (37), algo de eso veremos también más adelante.

\section{Los amantes I: la proyección del Imaginario}

Abramos entonces las primeras preguntas: ¿qué enigma guarda el Pathé Baby que Ramona le regala a Felipe? ¿Por qué él está "poseído", "abismado", "absorto", en fin, hipnotizado (242) por tal objeto, al que le da más importancia

\footnotetext{
8 Barthes, en la figura "iQué azul era el cielo!" (1998, 107-109) describe con claridad las cuatro: la captura, "una serie de encuentros felices"; las secuelas o "largo reguero de sufrimientos" y la salida (a lo largo del libro las salidas se ramifican y diferencian: una es el suicidio, otra la repetición de las etapas anteriores con una nueva Imagen, otra la entrada a una dialéctica que permita seguir en el amor ahora desembarazado de la hipnosis).
} 
que a la propia amada? Diremos de entrada que el proyector marca y hace explícito el reino del Imaginario, donde todo otro es anulado, todo es pura ilusión y no se es consciente de esta y su violencia. Para demostrarlo, habrá que mirar el objeto, en primera instancia, en términos técnicos, tal y como lo hace Delgado, quien "escrudiñaba en sus mínimos detalles [...] ya con un destornillador, ya con un trapo, ya con una aceitera" (242). Si recordamos el funcionamiento de dicho aparato, sabemos que es una pequeña imagen o fotograma que - a través de engranajes, espejos y una potente luz - se amplifica, bañando toda una superficie. Es una imagen "original" que se reproduce, se multiplica, se proyecta (y no olvidemos que proyecto y proyector mantienen una relación etimológica: lanzar hacia adelante, ir en una determinada dirección).

Así es como el yo de Felipe baña todo el mundo de la novela, negando toda posibilidad de alteridad (Villena 2003, 218, 228-229), a diferencia de lo afirmado por García Pabón. ${ }^{9}$ Villena detecta esto en la novela por su estructura iniciática clásica: el Bildungsroman que trata de representar toda la variedad de la noche paceña (200), pero solo la despoja de sentido para rellenarla de su propio "yo" generando un mito. ${ }^{10}$ Gesto que incluso contamina lo biográfico, el momento en que Saenz consigue un saco de aparapita y, antes de ponérselo, lo hace hervir para matar los piojos que contenía (anécdota referida por Saenz en "El aparapita de La Paz" 5). ${ }^{11}$ Hay que señalar, sin embargo, que Felipe está "abismado, absorto y ajeno, con los cabellos que se le caían sobre los ojos" (242). Es decir, no puede ver esta acción de proyección, es también una víctima del mundo en cuestión.

\footnotetext{
${ }^{9}$ Leonardo García Pabón parece caer en lecturas idealizadoras de la novela, pues ve en ella una clara separación con una "estructura basada en el autoritarismo" $(1998,247)$. Esto porque en la novela se mataría la figura del padre, resignificando la patria como el lugar donde amar (248). El amor, para García Pabón, en Saenz, es un "conocimiento del cuerpo muerto, de la patria íntima y del enigma del ser boliviano" que se manifiesta a partir del hacer, de la creación de una obra (247). Así, la visión de la novela, guiada por lo amoroso, lo íntimo, pondría en crisis los modelos heredados que niegan al otro (235).

${ }^{10}$ Aunque en el resto de este ensayo se verá la mirada dominante de Felipe en términos más técnicos y su injerencia sobre el camino amoroso, para confirmar su poder sobre la novela no hace falta más que poner a los personajes a hablar sobre un tema común: de Tamayo al Illimani, las afirmaciones de todos no serán dialécticas, sino monológicas.

${ }^{11}$ Anotemos brevemente que también en este capítulo se descubre algo sobre el saco de aparapita. Felipe, tras despertar al día siguiente sin recordar con total claridad lo acontecido la noche anterior, nota que su forro (es decir el interior del saco) está "como nuevo" (244). Entonces decide que solo un saco de aparapita sin forro podría ser tal y se lo arranca: se desgarra un lenguaje.
} 
Digamos que esta lectura "metatextual" del proyector, quizás a ojos de algún lector demasiado arbitraria, puede confirmarse con el análisis narratológico -a la manera de Genette- del capítulo: el narrador es heterodiegético con "focalización 0 ", es decir, es un dios que todo lo ve y todo lo sabe. Este narrador, sin embargo, se ubica en la perspectiva de Felipe -como se puede notar por el uso de deícticos que solo toman sentido desde el "yo" de Felipe, como "aquí" (241), "este" (241), "en este momento" (244) o verbos conjugados por la voz del narrador en primera persona como "creemos" (245)- sin por ello perder o problematizar esta omnisciencia; sabe perfectamente cómo se siente Ramona al ser desplazada por el proyector, objeto fetichista, Imaginario (242). Así se establece la ecuación "narrador=personaje", señalada por Antezana (citado en Villena 2003, 117) como un mecanismo usual del realismo boliviano, "monologante y autoritario". Dicho sea de paso, esta focalización se pone en crisis luego de la noche del cumpleaños, cuando Felipe ya no recuerda, ya no sabe nada. Pasa a la "focalización -1". Esta transformación, que sucede en otras ocasiones de la novela, del describir y saber todo al no poder describir nada, corresponde al inicio de la sustitución del Imaginario (del proyecto) por la Imagen (por lo Neutro) que, al ser única, permite al sujeto ver(se).



Figura 1: René Magritte, Los amantes I Fuente: Museo de Arte Moderno de Nueva York https://www.moma.org/collection/works/79933?classifications=any\&date_begi $\mathrm{n}=$ Pre-1850\&date_end=2021\&q=Magritte\&utf8=\%E2\%9C\%93\&with_images=1 
La anulación del otro, siguiendo las pistas de Antezana, ${ }^{12}$ pero también de Los amantes I, de Magritte (son los dos personajes tapados por sábanas en la Fig. 1). También Felipe cuelga una para poder ver la película de Chaplin. La sábana, digámoslo de paso, connota muerte, también afecta al "yo", frustrando cierto camino de autoconocimiento que solo aparecería en la ruptura de esta proyección. Entonces estamos ante un "yo" que, en palabras del propio Saenz, no puede mirar su propia cara (La piedra imán, 145). Se abre la pregunta, ¿qué tipo de imagen es la que Felipe proyecta sobre los demás? Retomamos entonces a Barthes en FDA, quien dice: "El discurso amoroso, por lo general, es una envoltura lisa que se ciñe a la Imagen, un guante muy suave en torno del ser amado. Es un discurso devoto, bienpensante" (36). También señala que el flechazo "es una hipnosis: soy fascinado por una imagen: primero sacudido, electrizado [...]; a continuación, envuelto, apabullado, inmovilizado, con la nariz pegada a la imagen (al espejo)" (206). Es decir que este juego de envolturas, a la manera de Los amantes $I$, anula a ambos sujetos en tanto reales, desplazándolos al Imaginario.

Este reino, como en las proyecciones de un Pathé baby, no es muy estable. Si uno se fija en detalle, entre fotograma y fotograma hay un espacio en negro, un parpadeo, fugaz, que nos anticipa la pronta ruptura de este estado de hipnosis: "para despertarla de su encantamiento, para romper la violencia de su Imaginario [...], bastaba darle una palmadita en el ala; ella se sacudía y recomenzaba a picotear" (206-207), confirma el autor francés. Sin embargo, rota una vez, puede volver a instaurarse.

Esta primera serie de preguntas despierta una segunda, íntimamente ligada a la primera. Ya sabemos bien, entonces, cómo funciona el proyector, pero no nos olvidemos de eso que proyecta. Citemos la descripción de la película:

a todo esto Chaplín, que se deshacía en acompasados gestos y se inclinaba con gran lentitud frente a una bella, repentinamente cayó como fulminado y con rapidez del relámpago al prosternarse ante la bella, y allá él si pedía misericordia más bien que no amor, mientras que la bella, que se hacía la diosa y estaba inmóvil como una estatua,

\footnotetext{
12 Luis $\mathrm{H}$. Antezana es quien verdaderamente abre un camino más problemático para leer la obra de Saenz. En su ensayo "Hacer y cuidar" (2011) revisa la dinámica entre el Yo y el Tú y afirma una lógica de máscaras y revelaciones. Ya en su pensamiento queda claro como el Yo, en la poesía de Saenz, se ve en un dilema: cómo nombrar al otro sin anularlo. En su trabajo sobre Felipe Delgado parece decir que el dilema se soluciona con mayor facilidad mediante el alcohol: "como si la introspección provocada por la bebida lo diseminara [a Felipe], al mismo tiempo, en todos los seres que lo rodean" $(2011,221)$.
} 
de pronto comenzó a saltar y brincar, se diría atacada por el mal de San Vito, y se puso a gesticular, ejecutando unos 600 dengues por minuto. (243-244)

En el juego de espejos -que es evidente desde el funcionamiento del proyector-, tendremos que entender que aquí (sin haber logrado identificar la película a la que Saenz podría estar haciendo referencia) Chaplin es un doble, un reflejo de Delgado, una transferencia del personaje. Al principio, la amada es víctima de la proyección del propio Chaplin (es la "bella" imagen, todavía no Imagen), así como Ramona para Felipe. Esto de alguna manera lo sabemos. Lo nuevo son dos elementos que aquí hacen su primera aparición, pero que son fundamentales en todo el capítulo.

El primero es una cuestión de ritmos. En la escena hay una marcada contraposición entre la lentitud (del enamorado inclinándose, de la bella como una estatua) que corresponde a la violencia del discurso amoroso sobre su objeto (recordemos, envoltura, entonces inmovilidad, imago), ${ }^{13}$ que es a la vez el ritmo en general de Felipe Delgado. ${ }^{14}$ Poco después aparece el término musical que define a la perfección este movimiento: el adagio (244). Pero frente a ese ritmo, el de la proyección que anula toda posibilidad de alteridad, se insinúa otro modelo, el de una alteridad extrema, que en la sinfonía de Brahms mencionada corresponde al più andante. Esta ocasionada primero por Chaplin, ${ }^{15}$ quien cae velozmente a los pies de la amada, pero luego por ella misma. El cuerpo de "la bella", enloquecido, en una velocidad inentendible, se hace visible, cobra vida.

El segundo es la aparición, que a lo largo del capítulo se hará insistente, de una contraposición entre amor y miedo, evidente cuando Chaplin pide

\footnotetext{
${ }^{13}$ Según el Diccionario de Psicoanálisis de Laplanche y Pontalis: "Prototipo inconsciente de personajes que orienta electivamente la forma en que el sujeto aprehende a los demás; se elabora a partir de las primeras relaciones intersubjetivas reales y fantaseadas con el ambiente familiar" (191).

${ }^{14}$ Este ritmo se relaciona a lo que Mauricio Souza señala como "estética púrpura" (2013, 21), es decir, algo armado de un sobre-exceso de fragmentos, de monólogos, que hacen difícil la lectura. Pero que, en este ensayo, también generan sentido: son parte del proyecto y del ordenamiento, son lo que hace parecer que ahí está el otro, cuando solo lo anulan.

${ }^{15}$ Y por Felipe que, al modo de los FDA, al ver darle más importancia a la película que a su amada, se asemeja al sujeto barthesiano que dice: "Al salir del cine, solo, rumiando mi problema amoroso, que la película no ha podido hacerme olvidar, lanzo esta curiosa exclamación: ibasta: que se acabe! pero: iquiero comprender (lo que me ocurre)!" (66). La caída, además, es un tema importante en Barthes, Marty anota: "Lo Neutro es por lo tanto suspensión (caída) de lo Imaginario [...] falta en lenguaje" (281). Solo a partir de ella se podría conjugar el binario razón/sentimiento.
} 
misericordia "más bien que no amor" (244). Sentimientos repetitivos en la figura del protagonista, que analizaremos más adelante. Marquemos que en la proyección hay algo más, algo ajeno, que escapa a la mirada ordenadora del protagonista, pero que a la vez es alguien de quien se puede ver su rostro:

En este momento, se iniciaba la función con una película de Carlitos Chaplín -en las tinieblas, Delgado se encontró contemplando una aparición totalmente ajena a las imágenes que se proyectaban sobre la pantalla. Unas facciones melancólicas y difusas revelaban con tenebrosa diafanidad el rostro de alguien, a quien él, Felipe Delgado, creía amar misteriosamente. En las tinieblas, los ojos eran un abismo, y el mirar, una helada soledad. Un soplo de júbilo quemaba la piel, con aire temible, en las tinieblas. (243)

El mirar de Felipe, entonces, corresponde a esa "helada soledad", donde él ya sabe todo. Los otros son una reducción de él mismo, han sido petrificados por su frío, y por eso él puede saber lo que piensan o sienten. A decir de Antezana, Felipe tiene una "complicidad" con el narrador (2011, 211-214), como hemos visto. Sin embargo, incluso ante ese frío, un soplo de júbilo se insinúa con aire temible, listo para quemarlo todo, quemar la piel.

\section{Los amantes II: del Imaginario a los rostros de la bella Imagen}

Sigamos indagando lo que el capítulo pone en juego: ¿qué rol juega Ramona en este baile? ¿Por qué habla de un beso que Felipe niega? Villena señala que Ramona podrá distraer a Felipe "de la ruta que le ha sido trazada" constituyéndose en un "Alter" $(2012,37)$. Falta decir que para este crítico (el único de los revisados que discute el capítulo aquí trabajado), ella lograría esto mediante los tres rostros que portaría a lo largo de la segunda parte de la novela. El primero sería el de identificación, reflejo del propio Delgado, evidente cuando se transforma en Ramón Delgada (Villena 2012, 38). Su segundo rostro sería el materno, no solo porque ambas, la madre de Felipe y la amada, tienen el mismo nombre, sino por la marca de muerte que comparten: la madre muere el día del nacimiento de su hijo y este ve la muerte de la segunda en su cumpleaños (39). Su tercer rostro sería prefigurar "al viejo de la cuarta caída", encarnando "esa falta, ese vacío" (39). Ella, una nueva Beatriz Portinari, instauraría el tiempo de la fiesta, de la comunión, del júbilo, al que Felipe le dirá adiós (Villena 2003, 237-239), tomando el camino de la Maldición y no del Sentido, como hará su sucesor en Los papeles de Narciso Lima-Achá, gracias a su amado Elbruz Ulme. Para complejizar aún más lo señalado podemos observar, en 
términos de los $F D A$, que tanto Ramona como Elbruz juegan el papel de una "Gradiva", aunque Elbruz con mayor éxito que la primera. Dice Barthes:

La antigua Gradiva, figura de la que ama sin saberlo, es percibida como una persona real; ahí está su delirio. Ella, para escapar suavemente, se conforma al principio a ese delirio; entra en él un poco, consiente en representar el papel de la Gradiva, en no destruir enseguida la ilusión y en no despertar bruscamente al soñador, en aproximar insensiblemente el mito y la realidad mediante lo cual la experiencia amorosa asume, hasta cierto punto, la misma función que una cura analítica. (145)

Esto se observa con cierta claridad en los gestos de Ramona al inicio de su relación con Felipe. Antes del capítulo en cuestión, Ramona sigue las proyecciones del protagonista y ambos viven en una alegría sin igual: Ramona se atreve a acompañar, el día de su propio cumpleaños, a Felipe a la bodega donde se emborracha con su grupo de compinches. $Y$ no solo tolera de buen humor la situación, también juega a ser el centro del espectáculo y su risa resuena entre el chocar de las copas (197-214). Pero la Gradiva tiene el poder de generar un desplazamiento, visible en la segunda versión de Los amantes II, donde los personajes siguen cubiertos por sábanas, por el Imaginario, pero ya no están pegados el uno al otro, hay un primer gesto de distancia. (Fig. 2)

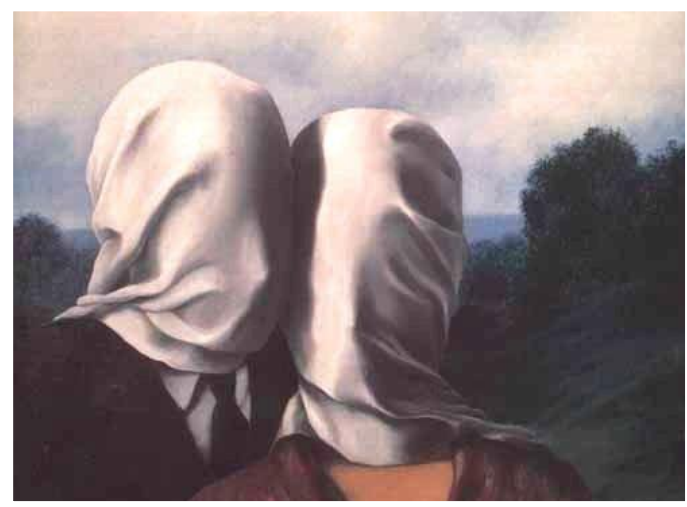

Figura 2: René Magritte, Los amantes II

Fuente: Galería Nacional de Australia

https://nga.gov.au/international/catalogue/detail.cfm?IRN=148052\&SiteID=2 
El hecho de que Ramona se adapte a la proyección de Felipe, es decir, que no sea exactamente ella la que porte simultáneamente los tres rostros, se puede ver en la siguiente cita:

Delgado veíase contemplando la imagen de aquel mirar alucinante que latía en las tinieblas con odio y con amor, con una luz de pureza y de encanto, con una sombra de depravación y de vicio; y, a dos pasos del interruptor de la luz, vislumbrando el perfil de Ramona que se recortaba sobre la pantalla, sentía un escalofrío de espanto ante aquel mirar, que miraba con una promesa hasta tal punto atroz y mortal, que ya podía derrumbarse jubilosamente el mundo. (244. Mi énfasis)

Donde también se puede apreciar un movimiento doble, el del odio y el amor, el de Ramón y Ramona. Ella es parte de la pantalla, encaja, es recortada. Ella misma no parece desear ser un otro, al menos en tanto Ramona (por algo será que en su nombre se lee un anagrama: "no amar", no porque con ella no haya una relación amorosa, sino porque es negada, cerrada). Esto se confirma con el tema del beso. El narrador señala:

[Ramona] encantada con el beso y con el abrazo que Delgado, en la función de cine, le había dado furtivamente -según dijo ella-, como verdadero enamorado; y sin embargo, él estaba absolutamente seguro de que no hubo tal, aunque, paradójicamente, no tenía ningún fundamento. Luego, como no podía recordar nada en concreto, todo se reducía sencillamente al sentimiento de que, al haber cambiado de súbito el estado de cosas, a partir del instante en que se hizo la oscuridad, Delgado no habría podido besar a nadie en el mundo, excepto a la aparición que se le apareció. (243)

Seguimos entonces en el escenario de una revelación, donde las cosas cambian bruscamente de un estado a otro. En ese marco, el beso no sería solamente "una expresión de cariño", como establece el Diccionario de la Real Academia de la Lengua, sino un gesto de unión, de simbiosis, de completitud. Es el equivalente al "Abrazo" de los FDA. ${ }^{16}$ Felipe, sujeto de esta experiencia, sin embargo, la niega, negando así su condición de enamorado (por el beso, Felipe era un "verdadero enamorado"). Pero solo la niega a medias, pues se le revela, en su confusión, que no podría besar a Ramona, pero sí a esa aparición que posteriormente se enlaza con Ramón. Entre lo que sucede sin suceder, algo de Neutro se va insinuando, algo de ruptura con la hipnosis.

16 Dice el enamorado: “abrazo que es un enlazamiento inmóvil: estamos encantados, hechizados: estamos en el sueño, sin dormir; estamos en la voluptuosidad infantil del adormecimiento" (24). 
No creemos que este desencaje se genere (solamente) porque el personaje tiene un deseo no "tradicional", homosexual; sino porque en el paso entre Ramona (cuya imagen está cortada, castrada) a Ramón, hay un momento en que Ramón es ambos, porta por un segundo los tres rostros de forma simultánea, en que por un momento es hombre-mujer, es intruso-amado, es lo Neutro. $Y$ ahí hay posibilidad de conocimiento amoroso, del otro. Lastimosamente, tal cosa dura poco, será por algo que en Ramón puede leerse el anagrama de "amor", donde el estar elevado a la enésima potencia, como veremos, es una alteridad extrema, la única posible en Saenz, pero posibilidad al final desechada, de todos modos, por este proyecto.

Esta posibilidad (digámoslo de paso) tomaría, como señalan Villena y Slowik, fuerza en la segunda novela de Saenz. En la segunda parte de Los papeles de Narciso Lima-Achá el autor pone, de forma evidente, sin "mecanismos de disimulo ante el poder normativo" (parafraseando a Amy Hollywood sobre la poesía de la Edad Media), un romance homosexual entre Narciso, el protagonista, y Elbruz Ulme, un joven alemán a quien él conoce en su viaje iniciático en barco a Europa. Un amor platónico que jala al amante a la “locura y la suprema razón" (Villena 2003, 300). Esto es permitido, sin embargo, porque desde que Narciso conoce a Elbruz, lo ve como hombre-mujer al mismo tiempo, su deseo (pronto cumplido) es verlo solo como mujer. En esa otra transexualización, que tarda más en llegar que en el Felipe Delgado, el otro muere en tanto otro.

\section{Los amantes III: la caída del Imaginario, la ruptura de la Imagen}

Así, entre dos ritmos, podríamos ampliar la idea central de la tesis de Slowik. ${ }^{17}$ En ambas novelas hay el vaivén entre los gestos conjuntos (Ramona

\footnotetext{
${ }^{17}$ Mirka Slowik continúa un camino de desmitificación. En su tesis de licenciatura, titulada Obsesión solitaria -escritura y lectura en la narrativa saenzeana a partir de la novela Los papeles de Narciso Lima-Achá de Jaime Saenz, reconoce una poética del autor. La crítica parte de la contraposición de las dos novelas de Saenz, para apuntar que "la obsesión solitaria en la narrativa de Jaime Saenz consistiría en una constante pugna entre la escritura y la lectura a solas y la escritura y la lectura conjunta, [...] en un intento de conciliación de ambas ideas" (111). En Felipe Delgado, afirma la autora, ganaría irremediablemente el camino solitario (se señala que Delgado descarta a Ramona, sin mencionar la escena homosexual de esta primera novela, importante precedente de la segunda), mientras que en Los papeles de Narciso Lima-Achá habría una tensión entre ambos, porque aun cuando las relaciones amorosas tampoco se mantendrían, existirían gestos amorosos a través de la escritura de los personajes de la novela.
} 
y Felipe viendo una película, Narciso y Elbruz escribiendo y leyendo) y solitarios; en ambos hay un fracaso del camino amoroso, del conocimiento que el amor implica. Aunque, digámoslo, en el segundo intento se ensaya con más intensidad lo amoroso, lo homosexual, la Imagen y lo Neutro. Por un lado, porque Narciso y Elbruz "duran" en la Imagen más tiempo y, por otro lado, porque luego de esa primera relación Narciso busca otras, llega a casarse, no escapa de este camino aunque fracasa en él (su esposa lo abandona). Teniendo este marco, exploremos las siguientes preguntas: ¿qué rol juega el intruso? ¿por qué aparece mediante la voz de los otros, como si no fuera parte del mundo visto por Felipe? Partamos, siguiendo el hilo de Villena, de que el intruso es un reflejo del propio protagonista. Esto podría sostenerse a partir de varias citas, por ejemplo:

La aparición se ocultaba en las tinieblas y luego asumía la figura del intruso; el intruso a su vez suplantaba a Felipe Delgado, y éste dudaba de su propia identidad y creía ser la aparición que se le apareció, de tal modo, que no sería otro que él, Felipe Delgado, quien habría abrazado y besado furtivamente a Felipe Delgado; y si Ramona se empeñaba en no creerlo, allá ella. (Felipe Delgado 245)

La claridad de la cita no debería dejar dudas. Este no es un momento aislado, la semejanza entre ambos es bien marcada a lo largo del capítulo: en el momento en que se relata que él se llama Ramón Delgada o cuando Beltrán señala que los dos (Felipe y el intruso) son personas distinguidas (casi marcando una diferencia de clase social con él mismo, mas una semejanza entre ellos dos). Esto confirma el escenario de un Narciso mítico cuyo error sería considerar esa proyección como real (Villena 2003, 218-221). ¿Estaremos acaso cayendo en el mismo error con esta lectura? Es posible, pero nos arriesgamos. Y para continuar, como si nada, nos preguntamos:

¿Pero no hay al menos una ambigüedad? Ya en el relato de Peña y Lillo se insiste en que este intruso es indefinible. Así, en cuatro ocasiones en menos de un párrafo se hace referencia a él como "joven, o señor, o, qué sé yo" (247248), alguien totalmente ajeno que nunca habría pisado la bodega. Por otro lado, se habla del temor que Felipe siente ante él, porque él sabe algo, no debería pasar inadvertido. De igual manera, el recatado Beltrán dice sobre este personaje:

Era un joven, o mancebo, o doncel, de carne y hueso, que usted llamaba Ramón, muy bien parecido él, qué diré yo del buen mozo; más bien bellísimo, hasta el extremo de haberle metido miedo a este nuestro común amigo, el cándido señor Peña y Lillo, y eso que era turnio, para más señas. (251) 
En la cita se marca la imposibilidad radical de definirlo, es turnio, es todo a la vez, es radicalmente cuerpo. No podemos evitar leer las connotaciones de la palabra "turnio", pues no solo se entendería en el sentido habitual, "de los ojos o de la mirada: estrábicos o torcidos" (DRAE), que remitiría a alguien cuyos ojos no están en la "posición habitual", es decir, están desviados. Es jerga habitual decir del homosexual que es un desviado, así este no estar en una posición "normal" se puede relacionar al deseo homosexual y su potencia subversiva, como también a la fluidez del intruso, a su vacío. Luego, se dice que refiere a alguien "que mira con ceño o demasiada severidad" (DRAE), es decir, hay un poder en esta mirada que puede modificar al otro, afectarlo. Más radicalmente, el turnio puede captar dos espacios al mismo tiempo, es decir, más allá de ser en sí mismo una desviación (sexual, política), es la acumulación de un todo en sí mismo, de lo indefinido e indescriptible. Es la corporalización de lo Neutro. Ya se habrá entendido cómo se juega con la Imagen en Saenz, entonces. El Imaginario, por tanto, ha caído. Lo confirma el beso que, posteriormente se confiesa, podrían haberse dado ambos personajes y el hecho de que Felipe afirme amarlo, como ya hemos analizado. Pero el miedo, la violencia, pronto anuncian que esta Imagen también será rota. Después de eso se cuenta como esta figura enloquece, lanza groserías y, a palos y patadas, despacha a ambos invitados, quedándose solo con el protagonista. Felipe, cuando ambos terminan su relato, les reclama lo siguiente:

-No seas imbécil -replicó Delgado ásperamente-. No hay tal amigo. Ustedes me vienen con Ramón por aquí y con Ramón por allá, como si no conocieran a Ramona, mi novia, y como si ella se hubiera vuelto hombre para que la llamen Ramón. (250)

Algo similar ocurre entre Narciso y Elbruz la noche en la que se conocen. Elbruz decide invitar a Narciso al bar del barco, empiezan a tomar de cuatro en cuatro las copas. Hasta que Elbruz empieza a lanzar groserías y a insultar a Narciso. Narciso a su vez responde:

-Ya pareces una prostituta -dije yo-. Capaz que te rompa el culo de un vergazo. Eres maricón, en tus ojos lo veo. Y seguramente como maricón no lo haces del todo mal." (178)

En ambos casos la violencia es explícita y es a través de ella que se rompe la Imagen. En el caso de Narciso, la restitución de la Imagen se vuelve imposible puesto que la violencia de la transexualización la impide. Hagamos un matiz que no será desarrollado: tal violencia algo tendrá también de 
potente, ¿o no era también a través de cuatro caídas que Felipe llega a conocerse? (Villena 2003, 198-216) ¿O no es Román Peña y Lillo (señalemos que Ramón y Román son anagramas el uno del otro), con quien hay una pelea en la que Felipe termina sangrando a la vuelta de su viaje al Valle de las Ánimas, ese otro que para Villena también genera distancia de esa tragedia, para él no tan trágica, del protagonista (248-256)? Dejamos tales preguntas pendientes, pues un desarrollo más amplio pedirían.

Lo importante aquí, como ya se ha dicho, es que esta ruptura pasa por una transexualización. Es por esta violencia que se pone en escena y en juego una alteridad extrema. Posteriormente, Narciso y Elbruz viven esta transexualización de forma definitiva (Narciso ve a Elbruz como a una mujer y ya no como la conjunción o puesta en crisis de lo masculino y lo femenino, con lo que este pierde su vacío, su potencialidad de no ser definido) y la relación termina. Lo mismo, de otro modo, vivirá Felipe. Es decir, esta Imagen no se sostiene por el miedo que él le tiene, y el otro al que se vuelve, Ramona, al ya no encajar en el proyecto de Saenz, deberá morir, como fatalmente sucede en la novela.

De alguna forma también es así en Los amantes III. (Fig. 3). En esta pintura se observa que los personajes ya no están cubiertos por sábanas. El Imaginario se ha roto, nos acercamos al paso de los sufrimientos a la salida



Figura 3: René Magritte, Los amantes III Fuente: Colección Privada

http://www.artnet.com/artists/ren\%C3\%A9-magritte/les-amants-iiib910mqOKNOnB_Gtflseb5A2 
(como ya decíamos, en el Felipe Delgado, el suicidio). Sin embargo, esta ruptura parece no ser permanente en el sentido de que ese otro se revela en parte, como una cabeza que flota sobre tu hombro. Una cabeza dulce como la bella Imagen. A diferencia de la pintura, en Saenz la corporalidad es central: pasa por los golpes, pasa por los gritos, la gesticulación y la locura. Pasa por ese segundo ritmo que hemos detectado, el del più andante. Este escenario es el que Barthes llamaría el de una "Alteración", "[c]uando la Imagen se altera, la envoltura de devoción se rasga; una conmoción trastoca mi propio lenguaje." (FDA 36). Podríamos decir, todavía de pasada, que el propio lector podría sufrir tal fenómeno, tal desplazamiento, ante el discurso saenceano.

\title{
4. Los amantes iv: el miedo a la (im)posibilidad del otro, de la Imagen
}

\begin{abstract}
En cuanto al espíritu del festín, solo asomaba un impreciso y vago recuerdo; en el festín, Delgado se sentía confundido y acobardado ante aquel intruso. Vanamente intentó arrojarlo con insultos y empellones. El intruso, haciendo toda la noche una gran ostentación de su papel, preguntaba descaradamente esto y aquello, hurgaba los cajones de la cómoda y sacaba pañuelos y se ponía loción [...] y miraba desvergonzadamente a Delgado, [...]. Bien podía ser un miserable pedigüeño, y sin embargo Delgado no osaba mirarlo; [tenía] el propósito de inmiscuirse en sus asuntos [...], todo para hacerle ver que alguien en este mundo lo conocía perfectamente y que [...] lo sabía todo. (245)
\end{abstract}

Hemos visto en la novela el funcionamiento de Felipe como un ente ordenador de un mundo donde se anula la posibilidad del otro. Es en un escenario específico (el departamento de Felipe), en un momento especial (el cumpleaños de Felipe), con la presencia de ciertos personajes (Peña y Lillo, Oblitas), que aparece el intruso, el otro, y con él se hace evidente un camino amoroso transexual. Como muestra la cita, este camino resulta insoportable para Felipe, quien va a expulsar a empellones al intruso. Felipe, entonces, tiene miedo, desea paz y calma, Reasume así su posición inicial: un dios omnisciente con control absoluto sobre su mundo, donde lo sabe todo, ubicándose en un lugar desde el cual ningún conocimiento nuevo puede revelársele a él. El intruso, como se ve en la cita, se entromete, revisa sus cajones (soberbia que podría leerse desde la lógica de lo escandaloso, del estereotipo homosexual). Felipe tiene mucho miedo. ¿Cómo un dios puede tener miedo? ¿Cómo leer este gesto? Poniendo en diálogo a Felipe con su homólogo (Narciso) en la segunda novela, esta posición se puede ver de manera más crítica. Dice Elbruz Ulme: 
¿Tú sabes quién es maricón? Es aquel que tiene miedo de mirarse cara a cara a sí mismo, y por eso camina por las calles sin atreverse a mirar a nadie de frente, y se pone colorado y estira el cogote, y luego se pone pálido y no sabe dónde meterse la vez que se topa con alguno que le gusta. $Y$ tiene una voz repugnante y una mirada falsa, y lo primero que hace es casarse para disimular. Los maricones me dan asco porque no son ni lo uno ni lo otro, ni hombre ni mujer, y se quedan a medias. [...] La diferencia absoluta puedes encontrarla en quien habla. Yo soy hombre, por una parte, y por la otra soy mujer, ciento por ciento de cada cual. (Los papeles de Narciso Lima-Achá 193).

En otras palabras, si entendemos que mirarse la cara a uno mismo es también atreverse a mirar la cara del otro, mirar la indefinible heterogeneidad de la fluidez de la vida, podemos decir que Felipe - como algunos de sus críticoses incapaz de ver los elementos movilizados por la heterogeneidad de su mundo. Precisamente reaccionando contra esta ceguera, Ramona va a llamarlo "maricón" en uno de los últimos diálogos que mantiene con él y que marca el ocaso de la relación amorosa:

-Loco degenerado -dijo-. iTe conozco! Por haberme fijado en ti, gusano malhabido, tengo que avergonzarme. Te castigaré. ¡Maldito pobretón metido a gente! No solo no soy capaz de denunciar a mi marido, por vicioso y por ratero, sino que soy muy capaz de denunciarte a ti, borracho infeliz, por inmoral, por impostor y por rufián, y para que lo sepas, por maricón. (Felipe Delgado 258. Mi énfasis)

Se explicitan los miedos de Felipe: miedo de mirar a la aparición, miedo de lo que esta parece saber de él, miedo de que comparta este conocimiento y "desenmascare" su verdadero deseo (245). Estos miedos lo paralizan, haciendo que ceda el control al intruso y lo deje obrar como quiera, destruyendo y desordenando su casa. Así, se coloca al intruso en un lugar de poder y se concreta la caída de la Imagen. Este "tener miedo", por otro lado, se confirma como una posición ante el mundo. Esta posición de alguna forma contamina la novela y la técnica narrativa (es decir, al autor), ${ }^{18}$ pues

\footnotetext{
18 Sabemos que trasladar valores ideológicos (como el miedo al amor) del personaje al narrador y de este al autor es un movimiento arriesgado y polémico. Para matizar entonces tal traslado nos vemos en la obligación de hacer algunas aclaraciones: 1) A la manera barthesiana, entendemos siempre al autor como un ser de papel (un texto fijado, un susurro a escuchar) y no uno real (una infinitud de textos siempre cambiantes). 2) No somos los primeros en afirmar tal cosa, nos respaldamos en una de las más importantes críticas de Saenz, Blanca Wiethüchter. En Memoria solicitada, un libro donde narra su relación con el autor, comenta lo siguiente sobre la última vez que lo vio vivo, tratando de hallar, sin éxito, algún manuscrito, y cayendo rendido:
} 
al final del capítulo se dice que todo lo sucedido no solo ha sido narrado con una extraña poca claridad, sino que ha sido un sueño. Es decir, a la manera de Los amantes IV (Fig. 4), esa otredad revelada, con la que se tiene un beso, un conocimiento, una pugna, termina por esfumarse, casi confundirse con los colores del fondo (lo que se ve radicalmente en la novela con la muerte de Ramona).

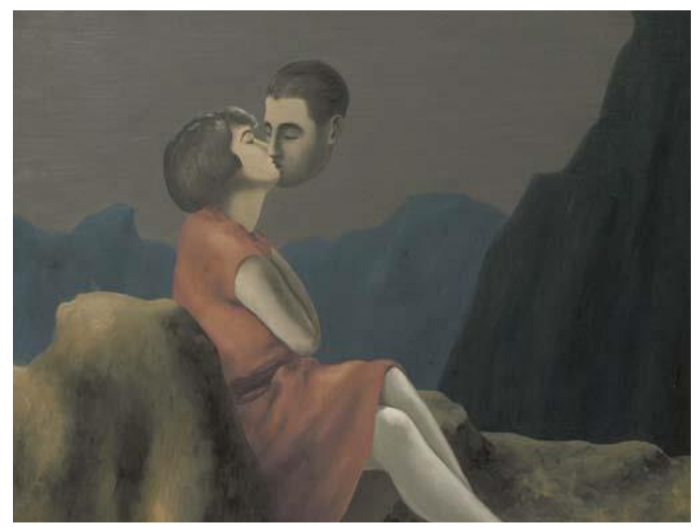

Figura 4: René Magritte, Los amantes IV Fuente: Colección Privada https://arthur.io/art/rene-magritte/the-lovers-iv

En ese sentido no importa si concordamos con Slowik al decir que en esta novela gana la pugna el camino solitario o, con Villena, al decir que en ambas novelas el final es común; sino señalar la existencia de gestos que tensionan la novela, que señalan al otro como un ser radical, que rompen la claridad de un narrador monológico que todo lo sabe. Veamos una cita:

\footnotetext{
"Después de unos minutos de intensa expectativa, $y$, al margen de todo lo previsible, balbuceó en forma apenas audible: sólo el amor salva. Esa frase de Goethe resumía probablemente lo que el párrafo buscado tan obstinadamente ocultó. La verdad es que no lo sé con certeza. Como fuera, la frase intentaba ser la resultante de una experiencia de vida y expresaba lo que nunca escribió, lo que profundamente, en todo su camino, lo acompañó, como una terrible carencia" (29. Énfasis del original). 3) Esta lectura de la crítica se ve acompañada, durante todo el libro, de afirmaciones del propio autor, donde dice, por ejemplo: "Tan infinita como es sobre la tierra esta infinita soledad del hombre, tan solo se remedia con la propia soledad. Con el amor se torna irremediable" (13).
} 
Con sobresalto, en medio de la inmovilidad y el silencio, Delgado miraba en torno de sí, y se sentía abrumado con la turbadora significación de este sueño -pues sueño había sido. Difícilmente pudo retornar a la realidad; la realidad no existiría, de no ser la irrealidad -pensaba Delgado. (250)

Tal movimiento es característico de una narrativa inmadura -ya señalada por Mauricio Souza (2013)- marcada por clichés. No solo el "llovía a torrentes", típico de la historia de fantasmas, sino también la suerte de amnesia de Felipe ("no me acuerdo"). Sin embargo, más allá del cliché, este olvido (que es también un cambio de focalización) podría explicarse por el temor a la censura social que puede recaer en una obra literaria que confronta a su comunidad de lectores a contenidos colectivamente reprimidos, como deseos queer y relaciones transexuales. A la manera de los "escritores del misticismo queer", como señala Amy Hollywood, que habrían acudido a una densidad retórica y a múltiples movimientos para que allá, en la Edad Media, el deseo no heteronormativo no sea visible y, según ella, evitar cualquier castigo y esquivar la censura. Aunque tal hipótesis sobre los autores de la Edad Media vale, quedaría la duda de por qué Saenz sí usa esos mecanismos en su primera novela y no en su segunda, aunque, claro, se podría argumentar que la segunda es póstuma.

Sin anular dicha interpretación, podríamos poner otra para finalizar el ensayo, más rica y compleja y que sigue el hilo de la argumentación que ha tratado de ponerse en juego hasta aquí: el escenario de un sueño y lo confuso, como el escenario del mítico Narciso, donde uno se ve a sí mismo, es el escenario de un autoconocimiento y un conocimiento del otro, pues en no poder describir(se) hay un No-Querer-Asir. El sueño revela, diría la voz del psicoanálisis, las pulsiones, deseos, profundidades del sujeto, y esto pondría en crisis o en entredicho aquello que proyecta sobre lo real, sobre el otro. Es decir, el territorio del Imaginario (ante la Imagen) también como un lugar ya no solo de engaños, sino de verdades; así como el territorio literario. Tal conocimiento se esfuma rápidamente para Felipe Delgado, cayendo en un mal Neutro, ${ }^{19}$ dando fin a tal movimiento (el de la intrusión y la exclusión del otro) con el fin de la relación con Ramona (y su muerte, como Alter intolerable al proyecto autoritario), anunciado justamente al final del capítulo:

\footnotetext{
${ }^{19}$ En Roland Barthes, el oficio de escribir, Éric Marty define el "mal Neutro" como "Neutro fallido que provocaba la vuelta a la castración [...] por la muerte", es el neutro de la narración, condenada a un fin (285).
} 
Fuerza es declarar que Delgado trató de averiguar la verdad de lo ocurrido; y hablando con Ramona, cautelosamente, le preguntó esto y aquello. Pero nada pudo sacar en limpio. Pues nada había ocurrido -según Ramona, a no ser lo de costumbre: una pelea. Por lo demás, las visitas de Ramona, extrañamente, tornábanse cada vez más breves, cada vez más espaciadas, según advirtió Delgado, en días subsiguientes a la fecha de su cumpleaños; difícilmente podía ocultar una intensa preocupación. Le daba mala espina un cambio tan brusco. (251)

Irremediablemente, al final de la novela Felipe se quita el cuerpo y desaparece en forma física. No obstante, como el suicida de los FDA, sigue existiendo, se convierte en un tormento para todos y pasa a formar parte del Imaginario paceño saenceano. Afirmemos ahora sí que, aunque para el personaje Felipe el conocimiento desaparece, para Felipe, la novela, no. Su narrador "externo", "heterodiegético", permite al lector, quien en sus manos tiene a Felipe y puede ver a Felipe como en un sueño, conservar tal saber, desplazarlo y quizás ver al otro, pero ya no en su locura, sino, a decir de Barthes, en su "suavidad" (FDA 22). Queda decir que en este ejercicio de análisis todavía quedan piezas por leer y que, sobre la obra se Saenz, quizás se han dicho "solamente la mitad de las cosas" (La piedra imán 9).

\section{Bibliografía Citada}

ANTEZANA, LUIS H. 2011 [1982]. "Felipe Delgado de Jaime Saenz". Ensayos escogidos. La Paz: Plural editores. 211-226.

---. 2011 [1978]. "Hacer y Cuidar". Ensayos escogidos 1976-2010. La Paz: Plural Editores. 231-264.

BARTHES, Roland. 1993 [1985]. "La lucha con el ángel: análisis textual del Génesis 32. 23-33. La aventura semiológica”. Ramón Alcalde, trad. Barcelona: Paidós editores. 281-308.

---. 1998 [1977]. Fragmentos de un discurso amoroso. Eduardo Molina, trad. México D.F.: Siglo XXI editores.

---. 2004 [1970]. S/Z. Nicolás Rosa, trad. Buenos Aires: Siglo XXI editores.

---. 2005 [1968]. “En nombre de la 'Nueva crítica', Roland Barthes contesta a Raymond Picard". El grano de la voz. Nora Pasternac, trad. Buenos Aires: Siglo XXI editores. 38-42.

BOULOUKOS, Beth. 2011. "Amor universal: Jaime Saenz's failed literary union". Mystical Queerings: Ecstasy and Transcendence in Latin American Texts. Tesis de Doctorado. Cornell University. 56-98. [https://ecommons.cornell.edu/bitstream/handle/1813/29234/bmb36 thesisPDF.pdf;jsessionid=2C2432D064D123E90B631E422128BCE1?seq uence=1] página descargada el 27 de septiembre, 2021.

GARCÍA PABÓN, Leonardo. 1998. "Paradójicos cadáveres nacionales: la poética de Jaime Saenz". La patria íntima. Alegorías nacionales en la literatura y el cine de Bolivia. La Paz: Plural editores. 213-248. 
GENETTE, Gérard. 1989 [1972]. Figuras III. Carlos Manzano, trad. Barcelona: editorial Lumen.

GIL OSTRIA, Camilo. 2020. "Felipe Delgado: entre el intruso y el marica". JALLA-México, 4-14 de agosto.

[https://www.facebook.com/ceiich.unam.mx/videos/16751667459775 03] página descargada el 25 de septiembre, 2021.

GONZÁLES, Gilmar. 1994. "La última novela de Jaime Sáenz: Los papeles de Narciso Lima-Achá". Hoy. La Paz, 9 de octubre de 1994.

HOLLYWOOD, Amy. 1995. "Queering the Beguines: Mechthild of Magdeburg, Hadewijch of Anvers, Marguerite Porete". Queer Theology: Rethinking the Western Body. Gerard Loughlin, comp. Singapure: Blackwell Publishing. 163-176.

LAPLANCHE, J. \& PONTALIS, J.B. 2004 [1996]. Diccionario de psicoanálisis. Buenos Aires: Paidós. [http://www.worldcat.org/oclc/966292384] página descargada el 25 de septiembre, 2021.

MAGRITTE, René. Los amantes I. 1928. Museo de arte moderno de Nueva York (MoMA).

[https://www.moma.org/collection/works/79933?classifications=any\& date_begin=Pre-

$1850 \&$ date_end $=2021 \& q=$ Magritte $\&$ utf $8=\% E 2 \% 9 C \% 93 \&$ with_images $=$ 1] página descargada el 4 de septiembre, 2021.

---. L Los amantes II. 1928. Galería Nacional de Australia.

[https://nga.gov.au/international/catalogue/detail.cfm?IRN=148052\&S itelD=2] página descargada el 4 de septiembre, 2021.

---. $\quad$ Los amantes III. 1928. Colección Privada.

[http://www.artnet.com/artists/ren\%C3\%A9-magritte/les-amants-iiib910mqOKNOnB_Gtflseb5A2] página descargada el 4 de septiembre, 2021.

---. Los amantes VI. 1928. Colección Privada.

[https://arthur.io/art/rene-magritte/the-lovers-iv] página descargada el 4 de septiembre, 2021.

MARTY, Éric. 2007 [2002]. Roland Barthes, el oficio de escribir. Horacio Pons, trad. Buenos Aires: Manantial.

MILLER, Jacques-Alain. 2021. "Entrevista de Jacques-Alain Miller a Éric Marty sobre "El sexo de los Modernos'”. Escuela Lacaniana de Psicoanálisis del Campo Freudiano. [https://elp.org.es/entrevista-de-jacques-alainmiller-a-eric-marty-sobre-el-sexo-de-los-modernos/] página descargada el 27 de septiembre, 2021.

SAENZ, Jaime. 2013 [1979]. Felipe Delgado. La Paz: Plural Editores.

---. 2014 [1991]. Los papeles de Narciso Lima-Achá. La Paz: Plural Editores.

---. 2015 [1989]. La piedra imán. La Paz: Plural Editores.

---. $\quad$ 1968. "El aparapita de La Paz". Mundo Nuevo 26-27. 4-8.

[file://C:/Users/elm15/Downloads/d06848e1b8c138eb0e9d911fbfd5f 970.pdf] página descargada el 27 de septiembre, 2021.

SLOWIK, Mirka Wanda. 2016. Obsesión solitaria -escritura y lectura en la narrativa saenzeana a partir de la novela Los papeles de Narciso LimaAchá de Jaime Saenz. Tesis de Licenciatura, Universidad Mayor de San Andrés, La Paz. 
[https://repositorio.umsa.bo/handle/123456789/6960] página descargada el 4 de septiembre, 2021.

SOUZA, Mauricio. 2013. "Citas para una historia de fantasmas: Llovía a torrentes". La Mariposa Mundial 21. 55-57.

VILLENA ALVARADO, Marcelo. 2012. "Felipe Delgado de Jaime Saenz". Estudio introductorio de Felipe Delgado. 15 Novelas Fundamentales. La Paz: Plural Editores. 19-47.

---. 2003. "Por los ríos y los campos: la narrativa de Jaime Saenz". Las tentaciones de San Ricardo. Siete ensayos para la interpretación de la narrativa boliviana del siglo XX. La Paz: Instituto de Estudios Bolivianos. 191-317.

WIETHÜCHTER, Blanca. 2003 [1989]. Memoria solicitada. La Paz: Editorial de la mujercita sentada.

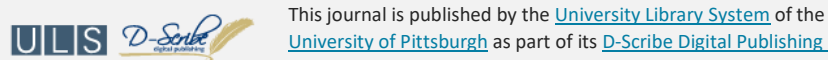
Program, and is cosponsored by the University of Pittsburgh Press. 